\title{
Wet-Treated MSWI Fly Ash Used as Supplementary Cementitious Material
}

\author{
Martin Keppert, ${ }^{1,2}$ Jamal Akhter Siddique, ${ }^{2}$ Zbyšek Pavlík, ${ }^{2}$ and Robert Černý ${ }^{2}$ \\ ${ }^{1}$ University Centre for Energy Efficient Buildings, Czech Technical University in Prague, Třinecká 1024, \\ 27343 Buštěhrad, Czech Republic \\ ${ }^{2}$ Department of Materials Engineering and Chemistry, Faculty of Civil Engineering, Czech Technical University in Prague, \\ Thákurova 7, 16629 Prague 6, Czech Republic
}

Correspondence should be addressed to Martin Keppert; martin.keppert@fsv.cvut.cz

Received 30 April 2015; Revised 2 July 2015; Accepted 7 July 2015

Academic Editor: Satoshi Horikoshi

Copyright (C) 2015 Martin Keppert et al. This is an open access article distributed under the Creative Commons Attribution License, which permits unrestricted use, distribution, and reproduction in any medium, provided the original work is properly cited.

\begin{abstract}
Municipal solid waste incineration (MSWI) is a common technique in treatment of domestic waste. This technique annually produces approximately $25 \mathrm{Mt}$ solid residues (i.e., bottom and fly ash) worldwide which is also a major issue in current research. In this research we are concerned with reusing the fly ash (FA) as supplementary cementitious material (SCM) in concrete. Such application solves the problem with heavy metal immobilization as well. To remove the high content of undesired soluble salts, number of washing treatments has been applied. Chemical composition of FA has been examined before and after treatments. The impact of cement substitution by FA in concrete was evaluated by measurement of its compressive strength and durability.
\end{abstract}

\section{Introduction}

Municipal solid wastes incineration (MSWI) generates millions of tons of residues worldwide every year and these quantities are expected to raise in the near future [1]. The incineration method has been accepted as effective method of dealing with MSW, leading to reduction in quantity of wastes of $65 \%-80 \%$ in weight and up to $90 \%$ in volume [2]. In addition, it produces energy from the heat combustion which can be used in different forms $[3,4]$. In general, incineration is found to be better than the landfilling [5]; the heat energy produced by the process of MSW is an important advantage of this method $[6,7]$. Bottom and fly ash are the two major by-products of MSWI; approximately $90 \%$ of this belongs to bottom ash whereas share of fly ash is only $10 \%$ of total ash/air pollution control residues produced. All over Europe, most of the municipal solid waste incineration residues are used in landfilling [8]. Such landfilling shows their negative impact on environment due to improper handling of their hazardous chemicals [9] and leads to the toxicity in soil due to heavy metal like lead and zinc [10]. MSWI ash typically contains various toxic organic substances, heavy metals, and salts particularly in the fly ash. At present, various researches inside and outside of Europe on MSWI bottom and fly ash are focused on safe disposal [11-14] and their utilization mainly for recycling into construction materials [15-17]. From time to time, many technologies have been developed for fly ash and can be grouped into two: (i) disposal of a treated (stabilized/solidified) ash and (ii) material recovery/utilization. Many researches have been done in utilization of MSWI fly ash like as a raw material for Portland clinker production [18], a component for ceramic tiles [19] in pavement asphalt [20] or glass-ceramics [21], and so forth. Utilization of MSWI fly ash as SCM seems to be its most perspective application.

Supplementary cementitious material (SCM) is a group of natural and man-made materials admixed in concrete to enhance some of its performance characteristics such as strength, workability, and durability. In addition to the environmental benefit provided on using these by-products, SCM can significantly improve the quality of the concrete [22-25]. Such replacement influences properties of fresh as well as hardened concrete [26]. This utilization of MSWI fly ash as Portland cement substitution $[27,28]$ improves total required energy for a building construction and also reduces $\mathrm{CO}_{2}$ emissions generated during the construction works. 
The municipal solid waste incineration fly ash is much different from coal fly ash uses worldwide and more complex in composition. MSWI fly ash is considered collective form of FA and APC (air pollution control) residue and called MSWI FA [29]. Fly ash comes from MSWI having mixture of crystalline and amorphous phases; mostly amorphousness is higher than $50 \%$ [30], composed of aluminous silicate with silicate material and sulphates [31-33]. High concentrations of heavy metals like $\mathrm{Zn}, \mathrm{Pb}$, As, $\mathrm{Cd}$, and $\mathrm{Hg}$ [34] and those rich in soluble salts (like halite and sylvite) present with organic micropollutants. Studies [34, 35] described that a number of weathering reactions can stimulate mineralogical changes in MSWI FA. These groups of components are considered as hazardous for environment. Such FA can be reused as SCM to substitute the Portland cement (PC) and utilized as binder in building materials only after proper treatment. However, the presence of large amounts of chlorides and sulfates is typical for all MSWI fly ashes and represents the main problem in the utilization of these ashes as Portland cement replacement in cementitious materials. The salts in untreated fly ash cause the increase of setting time and reduction of strength [36].

Fly ash which comes from MSWI is the most problematic ash due to the high content of possible dangerous substance. Solidification/stabilization (S/S), thermal treatment, and separation are the three renowned methods [37] in treatment of FAs. During solidification/stabilization treatments materials used with physical (specific surface area, porosity, etc.), mechanical (durability, mechanical strength, etc.), and chemical properties are able to immobilize hazardous species originally present in FA. Sulphides [37, 38], soluble phosphates [31,39-41], ferrous iron sulphate [42], and carbonates [40] are the major chemical agents used during this treatment of FA. Thermal process leads to melting of ash at high temperature and reducing the volume by $60 \%$ or more. Thermal treatment can be performed with [43] or without [44] an additive. The products of thermal treatment are more environmentally stable. In thermal treatment, techniques include microwave, vitrification, sintering, and melting of the FAs. This is the popular method of treatment applied by many researchers [45-50] in their research. Thermal methods are very efficient to destroy dioxins, furans, and other toxic organic compounds [28, 34, 51-53]. High amount of energy requirement is the major drawback of these methods [34]. Separation techniques include washing and leaching of the FA by water $[54,55]$ or by means of more sophisticated multiple step procedures [56]. On applying this method, chlorides can be extracted after solution evaporation and salts may be recovered [41, 57-59]. Several types of washing technique have been applied in particular for MSWI FA [60]; they displayed that it is possible to wash FA with water or with an acidic water solution. However, studies have reported that washing methods, using only water, are not very good for salt removal since large quantities of heavy metals (like $\mathrm{Pb}$ and $\mathrm{Zn}$ ) are also released simultaneously [61]. In present work, focus was to evaluate possibility of MSWI fly ash utilization as cement substitute in concrete. Substitutions of fly ash have been done before and after treatment, like direct washing with water and acids, inside and outside of the incinerator.

\section{Materials and Methods}

MSWI fly ash was studied in two states which were collected from a MSWI facility in Czech Republic; the first is untreated FA in raw state as collected in APC system of MSWI (denoted by FA-UW). It is mixture of ashes collected from boiler and electrostatic precipitator (ESP). Further several kinds of treated FA were studied: (a) the fly ash was subjected to the following treatment procedures: collecting fly ash from the same incinerator after inside treatment; leaching of FA by means of acid water solution coming from flue gas absorber (this washed ash is called fly ash incinerator washed, denoted by FA-IW); (b) water washing was performed in agitated vessel with L/S (liquid/solid) ratio equal to 5 (denoted by W5) and water washing with $\mathrm{L} / \mathrm{S}=10$ (denoted by W-10); (c) washing was performed by $0.1 \%$ solution of $\left(\mathrm{NH}_{4}\right)_{3} \mathrm{PO}_{4}$ with $\mathrm{L} / \mathrm{S}=10$ (denoted by WP); (d) washing was performed by diluted $\mathrm{HCl}$ at $\mathrm{pH} 1$ and $\mathrm{pH} 3$ with $\mathrm{L} / \mathrm{S}=10$ (denoted by WA-1 and WA-3, resp.). Solid residuum was filtered out and dried. In all cases, particles retained on $125 \mu \mathrm{m}$ sieve were removed since they have been too coarse to act as supplementary cementitious materials. The chemical composition of ashes was checked by XRF device Thermo ARL 9400 XP with a $\mathrm{Rh}$ anode end-window X-ray tube type 4GN fitted with $50 \mu \mathrm{m}$ Be window. All peak intensity data were collected in vacuum by help of software WinXRF. The obtained data were evaluated by standardless software Uniquant 4 . The particle size distribution was determined by laser diffraction analyser (Fritsch, Analysette 22 MicroTec plus) in ethanol in order to prevent possible hydration processes. Simultaneous TG/DSC thermal analysis was performed by Setaram calorimeter Labsys Evo under inert atmosphere from ambient temperature to $1000^{\circ} \mathrm{C}$. Morphology of ashes was observed by Scanning Electron Microscopy (Jeol JSM 6510). The phase composition of ashes was examined by help of XRD (Panalytical XPert Pro); the phase content quantification was performed by help of internal standard $(\mathrm{ZnO})$.

The untreated and treated ashes were applied as partial substitution of ordinary Portland cement (OPC; CEM I 42.5 $\mathrm{R})$ in mortars (Table 1). The specimens of mortars $(160 \times 40 \times$ $40 \mathrm{~mm}$ prisms) were stored at $100 \% \mathrm{RH}$ for 28 days and then their bending and compressive strength was measured ( EN 196-1). The influence of ashes on initial and final setting time of standard consistency cement paste was evaluated by Vicat apparatus (EN 196-3). The resistance of mortars to freezing/thawing action was tested by means of temperature cycling between -20 and $20^{\circ} \mathrm{C}$ and subsequent compressive strength determination (ČSN 73 1322).

\section{Results and Discussion}

There are six different ways of washing treatment that has been applied in this work on the FA generated by MSWI before use as a SCM. We can combine this washing treatment into three major groups, that is, washed directly by water (W-5 and W-10, collectively called fly ash water washed, denoted by FA-WW), washed by two different chemicals $(\mathrm{HCl}$ (at $\mathrm{pH} 1$ and $\mathrm{pH} 3)$ and $\left.\left(\mathrm{NH}_{4}\right)_{3} \mathrm{PO}_{4}\right)$ and $\mathrm{pH}$ outside the incinerator (WA-1, WA-3, and WP, resp., collectively 
TABLE 1: Composition of mortars.

\begin{tabular}{lcccc}
\hline & OPC & $\begin{array}{c}\text { Fly ash } \\
\mathrm{kg} / \mathrm{m}^{3}\end{array}$ & Sand & w/b \\
\hline Control & 460 & - & 1380 & 0.52 \\
$10 \%$ & 414 & 46 & 1380 & 0.52 \\
$20 \%$ & 368 & 92 & 1380 & 0.52 \\
$30 \%$ & 322 & 138 & 1380 & 0.52 \\
\hline
\end{tabular}

TABLE 2: Chemical composition of treated fly ashes (wt. \%).

\begin{tabular}{lccccccc}
\hline & \multirow{2}{*}{ FA-UW } & \multirow{2}{*}{ FA-IW } & \multicolumn{3}{c}{ FA-CW } & \multicolumn{2}{c}{ FA-WW } \\
& & & WP & WA-1 & WA-3 & W-10 & W-5 \\
\hline $\mathrm{SiO}_{2}$ & 15.6 & 12.2 & 18.1 & 19.4 & 19.2 & 19.1 & 19.0 \\
$\mathrm{Al}_{2} \mathrm{O}_{3}$ & 9.2 & 7.6 & 11.5 & 11.6 & 11.7 & 11.6 & 11.6 \\
$\mathrm{Fe}_{2} \mathrm{O}_{3}$ & 2.6 & 2.4 & 3.0 & 3.3 & 3.0 & 3.0 & 3.1 \\
$\mathrm{CaO}$ & 23.9 & 31.4 & 31.1 & 28.6 & 30.1 & 29.9 & 30.5 \\
$\mathrm{MgO}$ & 1.8 & 1.1 & 2.3 & 2.3 & 2.5 & 2.5 & 2.5 \\
$\mathrm{Na}_{2} \mathrm{O}$ & 9.4 & 0.5 & 2.6 & 3.0 & 2.6 & 2.9 & 2.5 \\
$\mathrm{~K}_{2} \mathrm{O}$ & 6.6 & 0.9 & 2.7 & 2.8 & 2.7 & 2.7 & 2.5 \\
$\mathrm{Cl}$ & 11.2 & 0.3 & 2.8 & 3.3 & 2.8 & 2.8 & 2.6 \\
$\mathrm{SO}_{3}$ & 11.5 & 37.2 & 13.2 & 15.8 & 13.9 & 14.1 & 14.0 \\
$\mathrm{P}_{2} \mathrm{O}_{5}$ & 1.3 & 1.1 & 3.0 & 1.8 & 1.8 & 1.7 & 1.7 \\
\hline
\end{tabular}

called fly ash chemically washed, denoted by FA-CW), and washed by the acid water solution coming from flue gas absorber in the incinerator (FA-IW). After implementation of all of the method, comparative observation of chemical composition of treated ashes mentioned in Table 2 was performed. All washing patterns are carried out in a similar way; the basic difference between unwashed FA and washed ashes is decrease of chlorides and alkali metals content. This decline of chlorides content is favorable for setting time of cementitious materials. Concentration of silicate and sulfates ions, as well as of heavy metals, in ashes relatively increased due to dissolution of soluble salts present in untreated ash. The approximate heavy metals contents in FA-WW and FA$\mathrm{CW}$ were also found to be generally higher than FA-UW.

Though the washed ashes were proposed to be used as SCM, the efficient immobilization of the present heavy metals was subsequently ensured by cementitious environment itself [62]. Chemical fraction of heavy metals in ashes mentioned in Table 3 was also performed by XRF spectroscopy. Heavy metals like $\mathrm{Cr}, \mathrm{Cu}, \mathrm{Hg}, \mathrm{Ni}, \mathrm{Cd}, \mathrm{Zn}$, and $\mathrm{Pb}$ are the most commonly found in MSWI fly ash; however, $\mathrm{Zn}$ and $\mathrm{Pb}$ normally exist in the largest amounts compared to other heavy metals.

The washing leads to refinement of ash particles (Figure 1) as a result of disintegration of chlorides which behave as a glue of larger particles agglomerates present in FA-UW. The retroaction of washing on particle size distribution was examined by grading analysis. The simple washing (W-10) constrains just minor particles refinement compared to FAUW. However, the washed ashes particles were larger than particles of Portland cement (PC) and size of ashes particles
TABLE 3: Content of heavy metals in fly ashes $(\mathrm{mg} / \mathrm{kg})$.

\begin{tabular}{lccccccc}
\hline \multirow{2}{*}{ Elements } & \multirow{2}{*}{ FA-UW } & \multirow{2}{*}{ FA-IW } & \multicolumn{3}{c}{ FA-CW } & \multicolumn{2}{c}{ FA-WW } \\
& & & WP & WA-1 & WA-3 & W-10 & W-5 \\
\hline As & BDL & BDL & BDL & BDL & BDL & BDL & BDL \\
$\mathrm{Ba}$ & 317.0 & 352.8 & 377.8 & 437.0 & 433.4 & 411.8 & 438.8 \\
$\mathrm{Cd}$ & 62.0 & BDL & 98.0 & 69.0 & 61.4 & 100.0 & 71.8 \\
$\mathrm{Co}$ & $\mathrm{BDL}$ & 3.0 & $\mathrm{BDL}$ & 9.0 & 6.4 & 11.8 & $\mathrm{BDL}$ \\
$\mathrm{Cr}$ & 131.4 & 127.2 & 158.8 & 145.0 & 162.8 & 164.2 & 164.2 \\
$\mathrm{Cu}$ & 204.6 & 190.2 & 308.4 & 254.0 & 316.4 & 298.8 & 310.0 \\
$\mathrm{Mn}$ & 266.4 & 215.2 & 345.5 & 354.8 & 354.8 & 354.2 & 368.6 \\
$\mathrm{Mo}$ & $\mathrm{BDL}$ & $\mathrm{BDL}$ & $\mathrm{BDL}$ & $\mathrm{BDL}$ & $\mathrm{BDL}$ & $\mathrm{BDL}$ & $\mathrm{BDL}$ \\
$\mathrm{Ni}$ & 17.2 & 23.0 & 16.4 & 16.6 & $\mathrm{BDL}$ & 17.4 & 15.8 \\
$\mathrm{~Pb}$ & 998.4 & 866.0 & 1498.6 & 1251.4 & 1463.6 & 1411.0 & 1451.8 \\
$\mathrm{Sb}$ & 218.4 & 561.8 & 365.2 & 311.8 & 405.2 & 386.8 & 356.8 \\
$\mathrm{Sn}$ & 302.4 & 502.6 & 486.8 & 430.0 & 526.2 & 510.4 & 477.4 \\
$\mathrm{~V}$ & 22.2 & 17.4 & 27.2 & 26.8 & 29.4 & 30.2 & 25.2 \\
$\mathrm{Zn}$ & 5912.8 & 3213.4 & 8949.6 & 6539.4 & 8580.0 & 8901.4 & 9206.6 \\
\hline
\end{tabular}

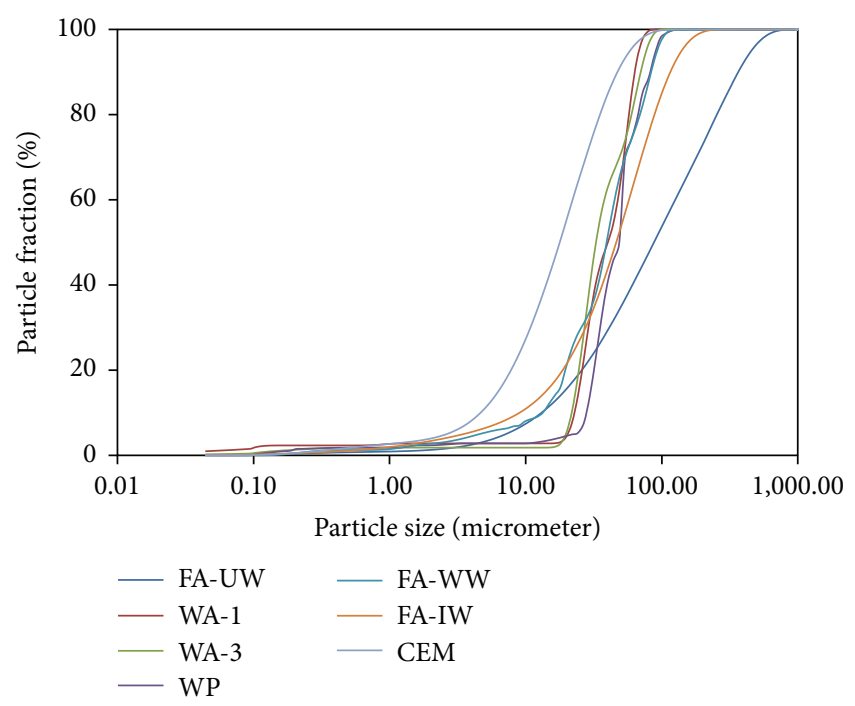

FIGURE 1: Particle size analysis of various treated ashes.

was close to standard requirement on pozzolanic admixture (remains on $45 \mu \mathrm{m}$ sieve lower than $40 \%$ ).

The impact of treated ashes on mortars compressive strength was applied as screening criterion in order to select the most promising way of FA treatment. The possible ability of ashes to replace Portland cement was checked by help of mortars, where ashes were dosed as pozzolanic admixture.

The compressive strength of prepared mortars (Table 1) was influenced by admixing of washed ashes (Figure 2). On performing first testing with FA-UW, that is, untreated ash, on replacement of $20 \%$ and $30 \%$, strength came down from $40 \mathrm{MPa}$ to $26 \mathrm{MPa}$ compared to standard whereas $10 \%$ shows better results, respectively. FA-WW-W-10 sample shows improvement in results and strengthen, the mortar; $\mathrm{W}-10$ produces outstanding results with $10 \%$ of replacement of $\mathrm{PC}$ and strength increases more than $40 \mathrm{MPa}$ (more than standard). 


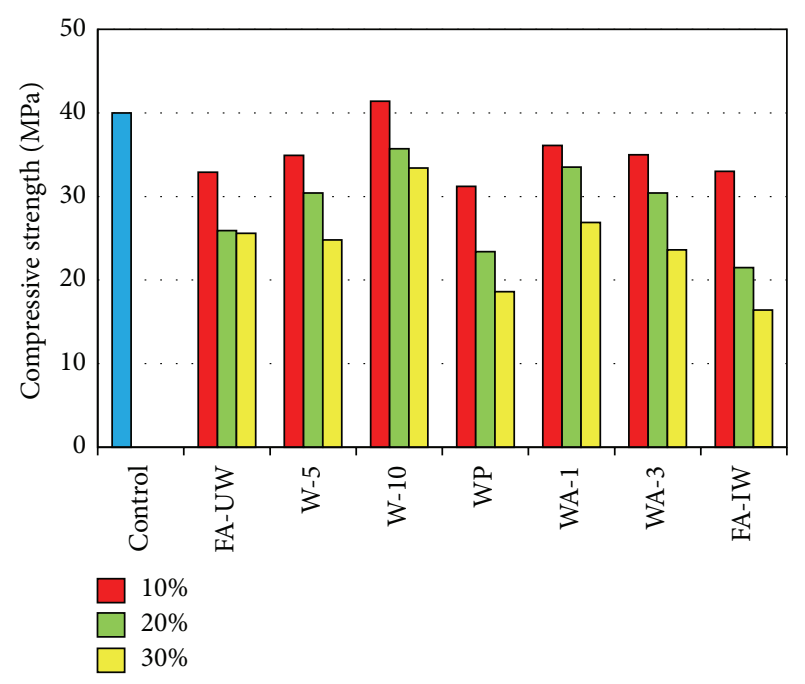

FIGURE 2: Compressive strength of mortars containing treated ashes as SCM.



FIgURE 3: SEM image of untreated sample FA-UW.

The resulting values of compressive strength of mortars indicated that the water washed fly ash (FA-WW-W-10) performed in the best way as SCM among the all tested washing methods. Further investigations have been applied to compare the washing performed in incinerator (FA-IW) and proposed laboratory washing (FA-WW-W-10, in further just FA-WW).

The determination of phase composition of ashes (Table 4) revealed important differences between them; the estimated content of amorphous phase indicated that a pozzolanic reaction can take place. Calcite was obviously not present in acid washed FA-IW. The efficiency of $\mathrm{NaCl}$ and $\mathrm{KCl}$ removal was higher in acid industrial washing than in laboratory. Very important was the difference in $\mathrm{CaSO}_{4}$ speciation when the crystallization of basanite was favored by acid environment while the water (brine in fact) washing caused the anhydrite crystallization.

The significance of water washing on the behaviour of fly ash was examined by means of SEM. In Figure 3 (untreated FA), it can be seen that all present species are forming agglomerates due to condensation of salts from flue gas in form of fine crystals. The water washing procedure implies (besides the soluble salts dissolution) also recrystallization of some
TABLE 4: Phase composition of ashes.

\begin{tabular}{lcccc}
\hline & & FA-UW & FA-IW & FA-WW \\
\hline Amorphous phase & - & 43.0 & 50.8 & 40.0 \\
Calcite & $\mathrm{CaCO}_{3}$ & 6.0 & - & 11.1 \\
Quartz & $\mathrm{SiO}_{2}$ & 8.5 & 7.4 & 8.0 \\
Halite & $\mathrm{NaCl}$ & 3.2 & - & 1.9 \\
Sylvite & $\mathrm{KCl}$ & 2.3 & - & 1.7 \\
Anorthite & $\mathrm{Ca}-\mathrm{feldspar}$ & 11.7 & - & - \\
Akermanite & $\mathrm{Ca}_{2} \mathrm{MgSi}_{2} \mathrm{O}_{7}$ & - & 4.4 & - \\
Gehlenite & $\mathrm{Ca}_{2} \mathrm{Al}_{2} \mathrm{SiO}_{7}$ & 10.8 & - & 11.6 \\
Muscovite & & 2.3 & - & - \\
Anhydrite & $\mathrm{CaSO}_{4}$ & 7.0 & - & 17.9 \\
Bassanite & $\mathrm{CaSO}_{4} \cdot 0.5\left(\mathrm{H}_{2} \mathrm{O}\right)$ & 3.8 & 28.8 & - \\
Gypsum & $\mathrm{CaSO}_{4} \cdot 2\left(\mathrm{H}_{2} \mathrm{O}\right)$ & - & 8.4 & - \\
\hline
\end{tabular}

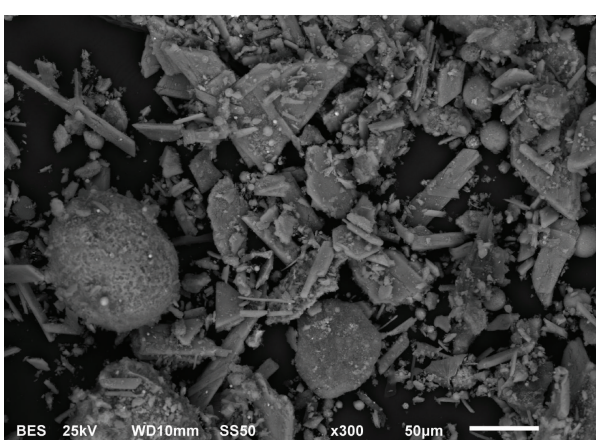

FIgURE 4: SEM image of treated FA-WW ash.

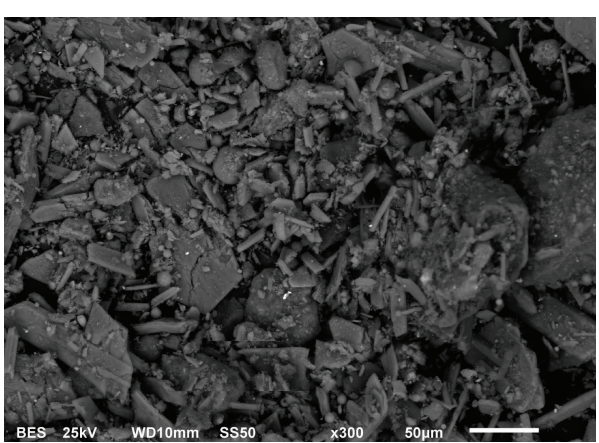

FIGURE 5: SEM image of FA-IW ash.

salts to larger particles and the silicate spherical particles were "washed" from salt cover and became more disseminate (Figure 4). Siliceous spherical particles are present in FAUW (Figure 3) as well, but condensed salt crystals cover all present solid species. Characteristic of fly ash FA-IW was conspicuously changed during the acid washing procedure. The treatment caused disintegration of most of soluble components (especially chlorides) and also recrystallization of other salts. It resulted in larger crystals (Figure 5) and also spherical particles are more articulate. The spherical species are composed mostly of $\mathrm{SiO}_{2}, \mathrm{CaO}$, and $\mathrm{Al}_{2} \mathrm{O}_{3}$ and thus are the valuable portion of the ash. 


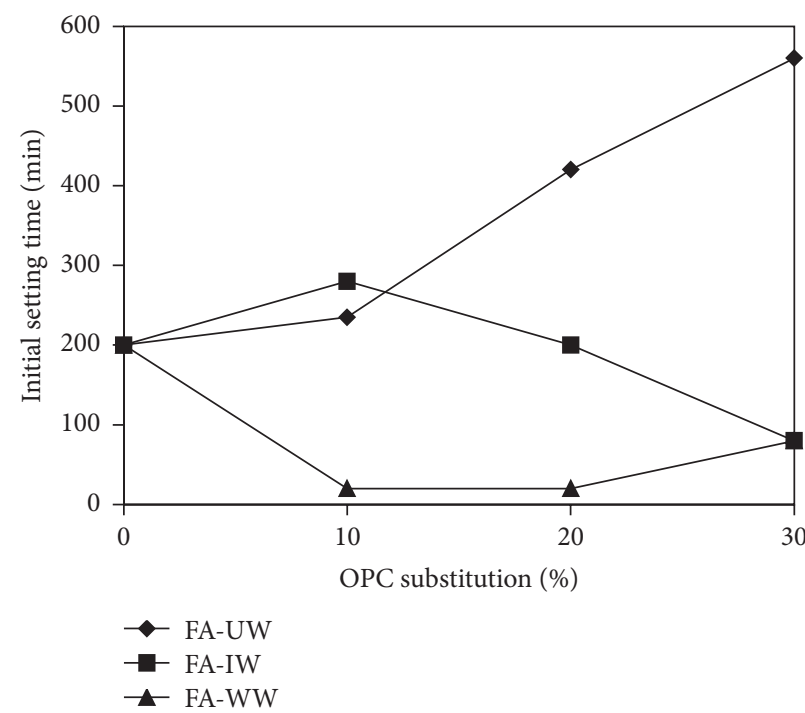

(a)

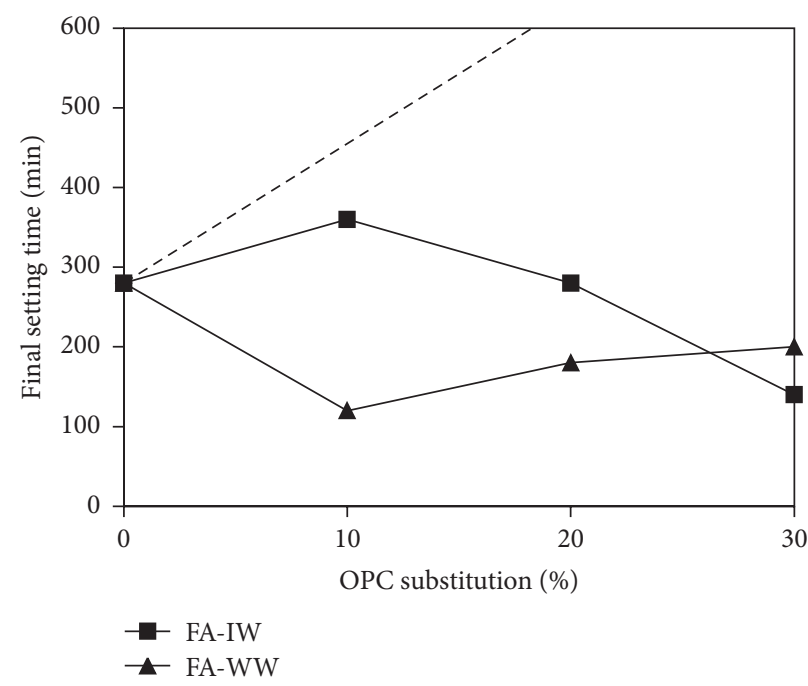

(b)

FIGURE 6: Comparison of initial and final setting time.

TABLE 5: Fundamental physical properties of FA-UW, FA-IW, and FA-WW.

\begin{tabular}{lccccc}
\hline Density & $\begin{array}{c}\text { Loose bulk } \\
\text { density } \\
\mathrm{g} / \mathrm{cm}^{3}\end{array}$ & $\begin{array}{c}\text { Specific surface } \\
\mathrm{m}^{2} / \mathrm{kg}\end{array}$ & $d_{50}$ & $\begin{array}{c}\text { Solubility } \\
\mathrm{cm}^{3}\end{array}$ & $\%$ \\
\hline FA-UW & 2.663 & 0.955 & 394 & 84 & 13.6 \\
FA-IW & 2.622 & 0.910 & 750 & 46 & 5.6 \\
FA-WW & 2.635 & 0.918 & 742 & 44 & 3.0 \\
\hline
\end{tabular}

The morphology of FA-UW was also influenced due to acid leaching. FA-IW is somewhat finer than FA-UW which is also delineated by its higher specific surface and lower $d_{50}$ (Table 5). The basic physical properties of FA-WW are comparable with FA-IW.

Unwashed ash FA-UW showed highly negative influence on initial and final setting time of fresh cement paste (Figure 6). FA-UW takes more than 10 hours in the final setting. On the contrary of this, the washed sample FA-WW improved remarkably in its parameters; the paste with cement substitution up to $30 \%$ got set faster than the control paste. The influence of FA-IW on setting kinetics was relatively neutral. Such big difference was not caused by a different content of retarding heavy metals $(\mathrm{Cu}, \mathrm{Pb}$, and $\mathrm{Zn})$ or chloride anion but probably has to be searched in speciation of sulphate anion when anhydrite is dominating in FAWW, FA-UW contained basanite and anhydrite, and FA-IW contained gypsum and bassanite. The anhydrite itself seems not to be hydration retarder.

The strength of cementitious composites is usually clearly linked to their porosity or bulk density (Figure 7). Both FA-UW and FA-IW reduced bulk density by about $5 \%$

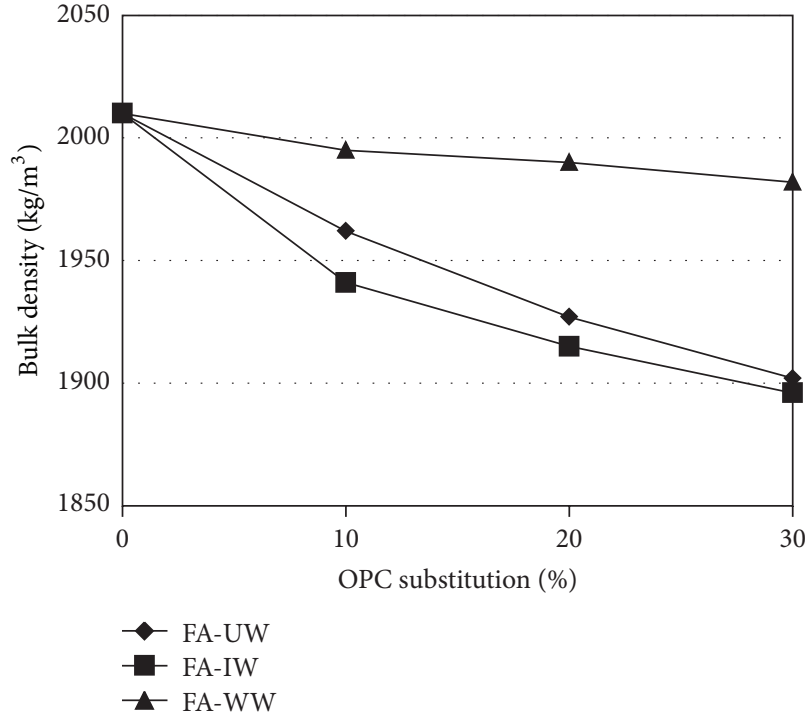

FIGURE 7: Influence of ashes on bulk density of mortars.

(at $30 \%$ substitution) while in case of FA-WW the reduction was negligible.

The impact of ashes on samples durability was evaluated by means of subjecting mortars to freezing/thawing cycles and determination of their compressive strength (Figures 8 , 9, and 10). Mortars with FA-UW had lower strength than the reference but especially strength of mortar with $20 \%$ cement substitution was increased during the experiment due to continuing of hydration process; the strength increase was not reduced significantly by freezing action. The cycling did not cause reduction of strength of particular mortars when compared to their initial (28 days of curing) state. 


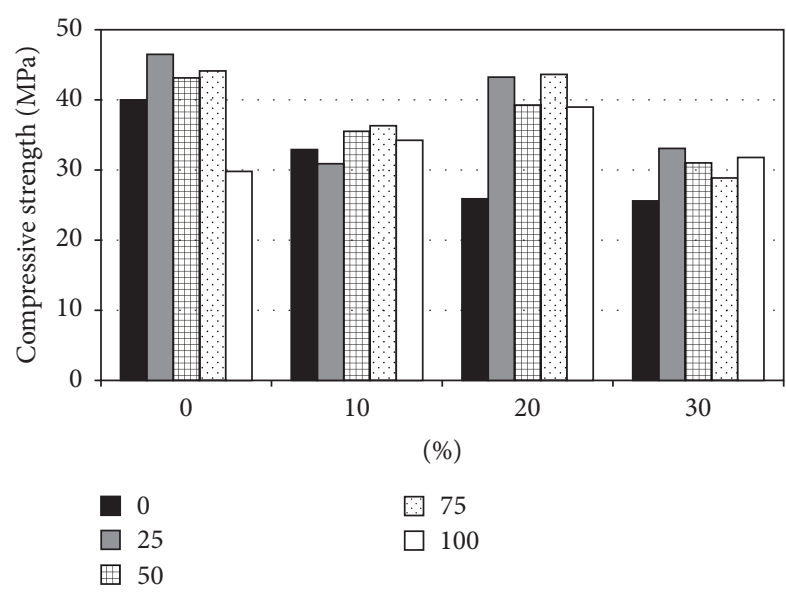

FIGURE 8: Compressive strength of mortars with FA-UW subjected to freezing cycles.

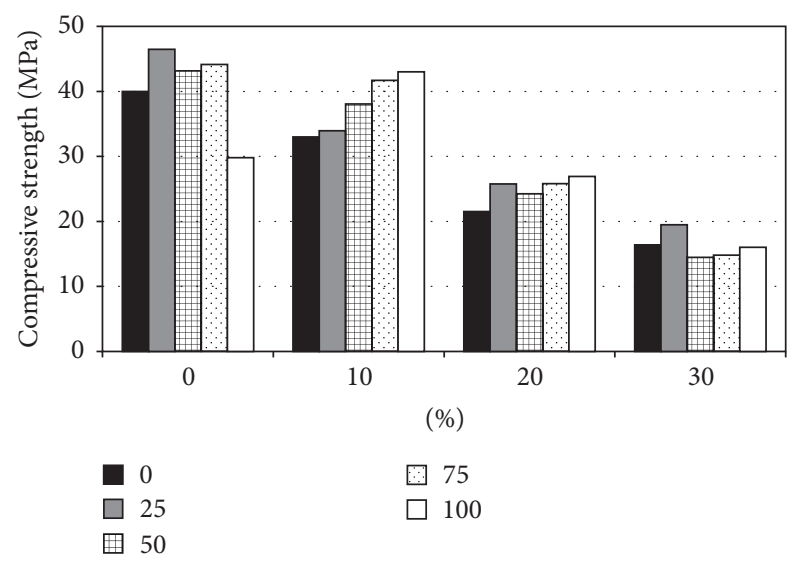

FIGURE 9: Compressive strength of mortars with FA-IW subjected to freezing cycles.

The industrially washed ash FA-IW worked generally as a poor cement substitute. On the other hand, the laboratory water washed FA-WW caused improvement of mortars behavior under freezing cycles; the strength of samples with 20 and 30\% OPC substitution was not reduced by cycling.

\section{Conclusion}

Chemical and physical characterization of untreated and treated fly ash from a modern MSWI facility was performed from the perspective of their possible utilization as pozzolana. Influence of washing solutions and at different $\mathrm{pH}$ on performance of MSWI fly ash as SCM was tested. The best ability to substitute PC showed fly ash washed by pure water $(\mathrm{L} / \mathrm{S}=10)$ where particles larger than $125 \mu \mathrm{m}$ were removed by sieving. The water treatment performed better than acid treatment procedure carried out in incinerator plant. The compressive strength of mortar with this water washed ash used as SCM was reduced just moderately but its resistance to freezing action was improved and the negative influence on setting kinetics observed in case of unwashed ash was suppressed.

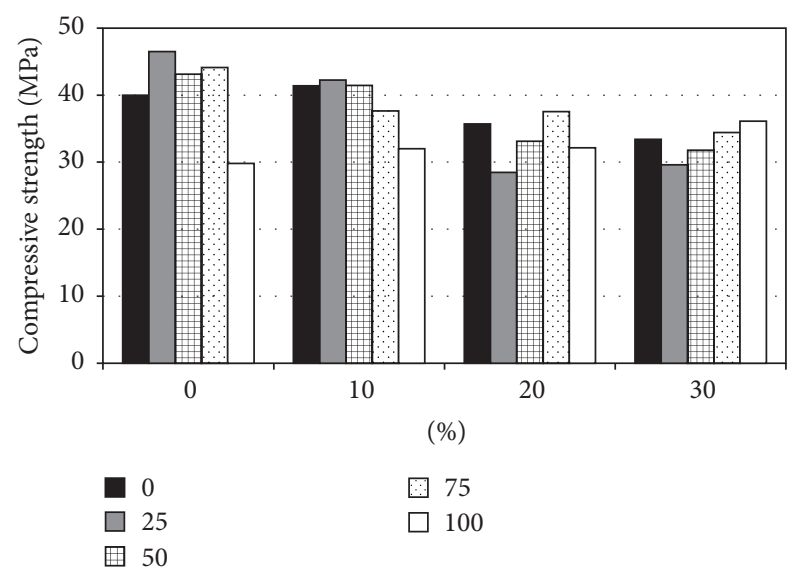

FIGURE 10: Compressive strength of mortars with FA-WW subjected to freezing cycles.

Unfortunately the washing procedure does not solve the high sulfates' content; only the recrystallization to larger crystals is taking place which means a long-time durability risk. The developed treatment method can be considered as efficient and cheap way of SCM production from MSWI fly ash.

\section{Conflict of Interests}

The authors declare that there is no conflict of interests regarding the publication of this paper.

\section{Acknowledgments}

This paper was supported by the European Social Fund within the framework of realizing the project Support of Inter-Sectoral Mobility and Quality Enhancement of Research Teams at Czech Technical University in Prague, no. CZ.1.07/2.3.00/30.0034 and by the Czech Science Foundation project no. GA14-04522S: Investigation of Processes at the Formation of Solid Structure in the Silicon OxidePortland Cement System in a Relation to the Properties of Binder.

\section{References}

[1] World-energy, 2013, https://www.worldenergy.org/wp-content/ uploads/2013/09/Complete_WER_2013_Survey.pdf.

[2] O. Hjelmar, "Disposal strategies for municipal solid waste incineration residues," Journal of Hazardous Materials, vol. 47, no. 13, pp. 345-368, 1996.

[3] P. M. Bierman and C. J. Rosen, "Phosphate and trace metal availability from sewage-sludge incinerator ash," Journal of Environmental Quality, vol. 23, no. 4, pp. 822-830, 1994.

[4] C. H. K. Lam, A. W. M. Ip, J. P. Barford, and G. McKay, "Use of incineration MSW ash: a review," Sustainability, vol. 2, no. 7, pp. 1943-1968, 2010.

[5] G. Finnveden, J. Johansson, P. Lind, and Å. Moberg, "Life cycle assessment of energy from solid waste-part 1: general methodology and results," Journal of Cleaner Production, vol. 13, no. 3, pp. 213-229, 2005. 
[6] P. Stehlík, "Contribution to advances in waste-to-energy technologies," Journal of Cleaner Production, vol. 17, no. 10, pp. 919931, 2009.

[7] W.-T. Tsai, "Analysis of the sustainability of reusing industrial wastes as energy source in the industrial sector of Taiwan," Journal of Cleaner Production, vol. 18, no. 14, pp. 1440-1445, 2010.

[8] S. E. Vergara and G. Tchobanoglous, "Municipal solid waste and the environment: a global perspective," Annual Review of Environment and Resources, vol. 37, pp. 277-309, 2012.

[9] M. Li, J. Xiang, S. Hu et al., "Characterization of solid residues from municipal solid waste incinerator," Fuel, vol. 83, no. 10, pp. 1397-1405, 2004.

[10] Y. H. Li, X. Peng, D. W. Li, and K. Yang, “The environmental toxicity of heavy metals in municipal solid waste incineration fly ash," Applied Mechanics and Materials, vol. 71-78, pp. 47604764, 2011.

[11] M. Izquierdo, X. Querol, A. Josa, E. Vazquez, and A. LópezSoler, "Comparison between laboratory and field leachability of MSWI bottom ash as a road material," Science of the Total Environment, vol. 389, no. 1, pp. 10-19, 2008.

[12] Y.-C. Lin, S. C. Panchangam, C.-H. Wu, P.-K. A. Hong, and C.F. Lin, "Effects of water washing on removing organic residues in bottom ashes of municipal solid waste incinerators," Chemosphere, vol. 82, no. 4, pp. 502-506, 2011.

[13] F. Colangelo, R. Cioffi, F. Montagnaro, and L. Santoro, "Soluble salt removal from MSWI fly ash and its stabilization for safer disposal and recovery as road basement material," Waste Management, vol. 32, no. 6, pp. 1179-1185, 2012.

[14] G. Cornelis, T. V. Gerven, and C. Vandecasteele, "Antimony leaching from MSWI bottom ash: modelling of the effect of $\mathrm{pH}$ and carbonation," Waste Management, vol. 32, no. 2, pp. 278286, 2012.

[15] J. P. G. M. Schreurs, H. A. Van der Sloot, and C. Hendriks, "Verification of laboratory-field leaching behavior of coal fly ash and MSWI bottom ash as a road base material," Waste Management, vol. 20, no. 2-3, pp. 193-201, 2000.

[16] T. Mangialardi, "Disposal of MSWI fly ash through a combined washing-immobilisation process," Journal of Hazardous Materials, vol. 98, no. 1-3, pp. 225-240, 2003.

[17] M. Nishigaki, "Producing permeable blocks and pavement bricks from molten slag," Waste Management, vol. 20, no. 2-3, pp. 185-192, 2000.

[18] C. H. K. Lam, J. P. Barford, and G. McKay, "Utilization of municipal solid waste incineration ash in Portland cement clinker," Clean Technologies and Environmental Policy, vol. 13, no. 4, pp. 607-615, 2011.

[19] Z. Haiying, Z. Youcai, and Q. Jingyu, "Study on use of MSWI fly ash in ceramic tile," Journal of Hazardous Materials, vol. 141, no. 1, pp. 106-114, 2007.

[20] Y. J. Xue, H. B. Hou, S. J. Zhu, and J. Zha, "Utilization of municipal solid waste incineration ash in stone mastic asphalt mixture: pavement performance and environmental impact," Construction and Building Materials, vol. 23, no. 2, pp. 989-996, 2009.

[21] T. W. Cheng and Y. S. Chen, "On formation of CaO- ${ }_{A} \mathrm{l}_{2} \mathrm{O}_{3}-\mathrm{SiO}_{2}$ glass-ceramics by vitrification of incinerator fly ash," Chemosphere, vol. 51, no. 9, pp. 817-824, 2003.

[22] O. Holčapek, P. Reiterman, and P. Konvalinka, "Fracture characteristics of refractory composites containing metakaolin and ceramic fibers," Advances in Mechanical Engineering, vol. 7, no. 3, 2015.
[23] N. Bouzoubaâ, A. Bilodeau, V. Sivasundaram, B. Fournier, and D. M. Golden, "Development of ternary blends for high-performance concrete," ACI Materials Journal, vol. 101, no. 1, pp. 11-19, 2004.

[24] M. D. A. Thomas, M. H. Shehata, S. G. Shashiprakash, D. S. Hopkins, and K. Cail, "Use of ternary cementitious systems containing silica fume and fly ash in concrete," Cement and Concrete Research, vol. 29, no. 8, pp. 1207-1214, 1999.

[25] K. M. Smith, A. J. Schokker, and P. J. Tikalsky, "Performance of supplementary cementitious materials in concrete resistivity and corrosion monitoring evaluations," ACI Materials Journal, vol. 101, no. 5, pp. 385-390, 2004.

[26] E. Vejmelková, M. Pavlíková, M. Keppert et al., "High performance concrete with Czech metakaolin: experimental analysis of strength, toughness and durability characteristics," Construction and Building Materials, vol. 24, no. 8, pp. 1404-1411, 2010.

[27] C. S. Kirby and J. D. Rimstidt, "Mineralogy and surface properties of municipal solid waste ash," Environmental Science and Technology, vol. 27, no. 4, pp. 652-660, 1993.

[28] C. Ferreira, A. Ribeiro, and L. Ottosen, "Possible applications for municipal solid waste fly ash," Journal of Hazardous Materials, vol. 96, no. 2-3, pp. 201-216, 2003.

[29] A. De Boom and M. Degrez, "Belgian MSWI fly ashes and APC residues: a characterisation study, Waste Management, vol. 32, no. 6, pp. 1163-1170, 2012.

[30] E. Bontempi, A. Zacco, L. Borgese, A. Gianoncelli, R. Ardesi, and L. E. Depero, "A new method for municipal solid waste incinerator (MSWI) fly ash inertization, based on colloidal silica," Journal of Environmental Monitoring, vol. 12, no. 11, pp. 2093-2099, 2010.

[31] T. T. Eighmy, J. D. Eusden Jr., J. E. Krzanowski et al., “Comprehensive approach toward understanding element speciation and leaching behavior in municipal solid waste incineration electrostatic precipitator ash," Environmental Science \& Technology, vol. 29, no. 3, pp. 629-646, 1995.

[32] P. Fermo, F. Cariati, A. Pozzi et al., "The analytical characterization of municipal solid waste incinerator fly ash: methods and preliminary results," Fresenius' Journal of Analytical Chemistry, vol. 365, no. 8, pp. 666-673, 1999.

[33] P. Fermo, F. Cariati, A. Pozzi, M. Tettamanti, E. Collina, and D. Pitea, "Analytical characterization of municipal solid waste incinerator fly ash: part II," Fresenius' Journal of Analytical Chemistry, vol. 366, no. 3, pp. 267-272, 2000.

[34] T. Sabbas, A. Polettini, R. Pomi et al., "Management of municipal solid waste incineration residues," Waste Management, vol. 23, no. 1, pp. 61-88, 2003.

[35] C. Speiser, T. Baumann, and R. Niessner, "Morphological and chemical characterization of calcium-hydrate phases formed in alteration processes of deposited municipal solid waste incinerator bottom ash," Environmental Science and Technology, vol. 34, no. 23, pp. 5030-5037, 2000.

[36] S. Rémond, P. Pimienta, and D. P. Bentz, "Effects of the incorporation of municipal solid waste incineration fly ash in cement pastes and mortars: I. Experimental study," Cement and Concrete Research, vol. 32, no. 2, pp. 303-311, 2002.

[37] A. J. Chandler, T. T. Eighmy, O. Hartlén et al., Municipal Solid Waste Incinerator Residues, Studies in Environmental Science, Elsevier Science, Amsterdam, The Netherlands, 1997.

[38] H. Katsuura, T. Inoue, M. Hiraoka, and S. Sakai, "Full-scale plant study on fly ash treatment by the acid extraction process," Waste Management, vol. 16, no. 5-6, pp. 491-499, 1996. 
[39] R. Derie, "A new way to stabilize fly ash from municipal incinerators," Waste Management, vol. 16, no. 8, pp. 711-716, 1996.

[40] O. Hjelmar, H. Birch, and J. B. Hansen, "Development of a process for treatment of APCresidues from MSW incinerators prior to landfilling," in Proceedings of the 7th International Landfill Symposium (Sardinia '99), vol. 1, pp. 543-548, 1999.

[41] A. Nzihou and P. Sharrock, "Calcium phosphate stabilization of fly ash with chloride extraction," Waste Management, vol. 22, no. 2, pp. 235-239, 2002.

[42] K. Lundtorp, D. L. Jensen, M. A. Sørensen, E. P. B. Mogensen, and T. H. Christensen, "Stabilization of APC-residues with FeSO4," in Proceedings of the 7th International Landfill Symposium (Sardinia '99), vol. 1, pp. 549-556, 1999.

[43] A. Polettini, R. Pomi, L. Trinci, A. Muntoni, and S. Lo Mastro, "Engineering and environmental properties of thermally treated mixtures containing MSWI fly ash and low-cost additives," Chemosphere, vol. 56, no. 10, pp. 901-910, 2004.

[44] K. L. Lin, K. S. Wang, B. Y. Tzeng, and C. Y. Lin, “The reuse of municipal solid waste incinerator fly ash slag as a cement substitute," Resources, Conservation and Recycling, vol. 39, no. 4, pp. 315-324, 2003.

[45] P. O. Auer, B. Eichler, C. Ludwig, S. Stucki, and J. Wochele, "Recycling heavy metals by the method of fractionated condensation," in Proceedings of the 4th World Congress: Recovery, Recycling, Reintegration, vol. 4, pp. 328-333, Geneva, Switzerland, 1999.

[46] A. Jakob, S. Stucki, and P. Kuhn, "Evaporation of heavy metals during the heat treatment of municipal solid waste incinerator fly ash," Environmental Science and Technology, vol. 29, no. 9, pp. 2429-2436, 1995.

[47] A. Jakob, S. Stucki, and R. W. Struis, "Complete heavy metal removal from fly ash by heat treatment: influence of chlorides on evaporation rates," Journal of Environmental Science and Technology, vol. 30, no. 11, pp. 3275-3283, 1996.

[48] S. Stucki and A. Jakob, "Thermal treatment of incinerator fly ash: factors influencing the evaporation of $\mathrm{ZnCl}_{2}$," Waste Management, vol. 17, no. 4, pp. 231-236, 1998.

[49] H. Lutz, Detoxification of filter ashes from municipal solid waste incinerators [Ph.D. thesis], ETH Zürich, Zürich, Switzerland, 2002.

[50] Z. Youcai, S. Stucki, C. Ludwig, and J. Wochele, "Impact of moisture on volatility of heavy metals in municipal solid waste incinerated in a laboratory scale simulated incinerator," Waste Management, vol. 24, no. 6, pp. 581-587, 2004.

[51] E. Bernardo, E. Bonomo, and A. Dattoli, "Optimisation of sintered glass-ceramics from an industrial waste glass," Ceramics International, vol. 36, no. 5, pp. 1675-1680, 2010.

[52] C. Izumikawa, "Metal recovery from fly ash generated from vitrification process for MSW ash," Waste Management, vol. 16, no. 5-6, pp. 501-507, 1996.

[53] Y. J. Park and J. Heo, "Vitrification of fly ash from municipal solid waste incinerator," Journal of Hazardous Materials, vol. 91, no. 1-3, pp. 83-93, 2002.

[54] X. Gao, W. Wang, T. Ye, F. Wang, and Y. Lan, "Utilization of washed MSWI fly ash as partial cement substitute with the addition of dithiocarbamic chelate," Journal of Environmental Management, vol. 88, no. 2, pp. 293-299, 2008.

[55] L. Bertolini, M. Carsana, D. Cassago, A. Q. Curzio, and M. Collepardi, "MSWI ashes as mineral additions in concrete," Cement and Concrete Research, vol. 34, no. 10, pp. 1899-1906, 2004.
[56] J. E. Aubert, B. Husson, and A. Vaquier, "Use of municipal solid waste incineration fly ash in concrete," Cement and Concrete Research, vol. 34, no. 6, pp. 957-963, 2004.

[57] J. M. Chimenos, A. I. Fernández, A. Cervantes, L. Miralles, M. A. Fernández, and F. Espiell, "Optimizing the APC residue washing process to minimize the release of chloride and heavy metals," Waste Management, vol. 25, no. 7, pp. 686-693, 2005.

[58] D. François and C. Criado, "Monitoring of leachate at a test road using treated fly ash from municipal solid waste incinerator," Journal of Hazardous Materials, vol. 139, no. 3, pp. 543-549, 2007.

[59] E. Mulder, "Pre-treatment of MSWI fly ash for useful application," Waste Management, vol. 16, no. 1-3, pp. 181-184, 1996.

[60] D. Amutha Rani, A. R. Boccaccini, D. Deegan, and C. R. Cheeseman, "Air pollution control residues from waste incineration: current UK situation and assessment of alternative technologies," Waste Management, vol. 28, no. 11, pp. 2279-2292, 2008.

[61] M. J. Quina, J. C. Bordado, and R. M. Quinta-Ferreira, “Treatment and use of air pollution control residues from MSW incineration: an overview," Waste Management, vol. 28, no. 11, pp. 2097-2121, 2008.

[62] M. Pohořelý, M. Šyc, M. Tošnarová, M. Zychová, M. Keppert, and M. Punčochář, "Immobilization of heavy metals in MSWI ashes," Paliva, vol. 2, pp. 113-118, 2010. 

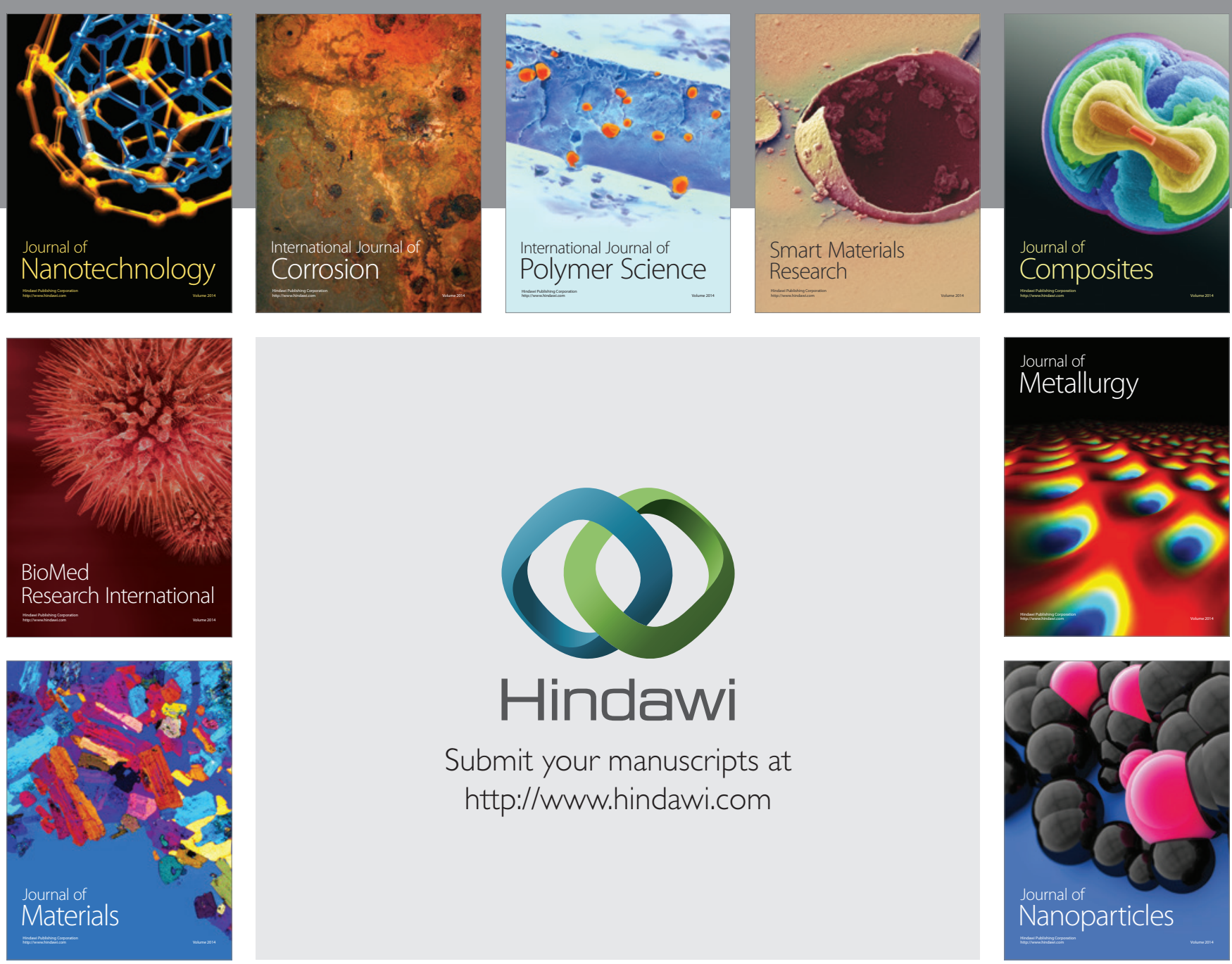

Submit your manuscripts at http://www.hindawi.com
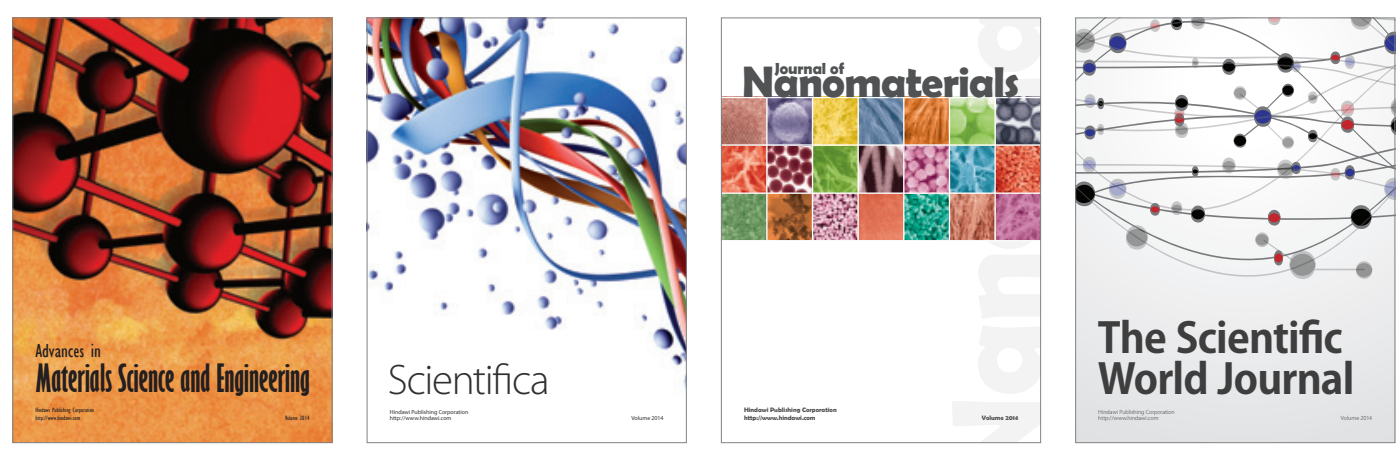

\section{The Scientific World Journal}
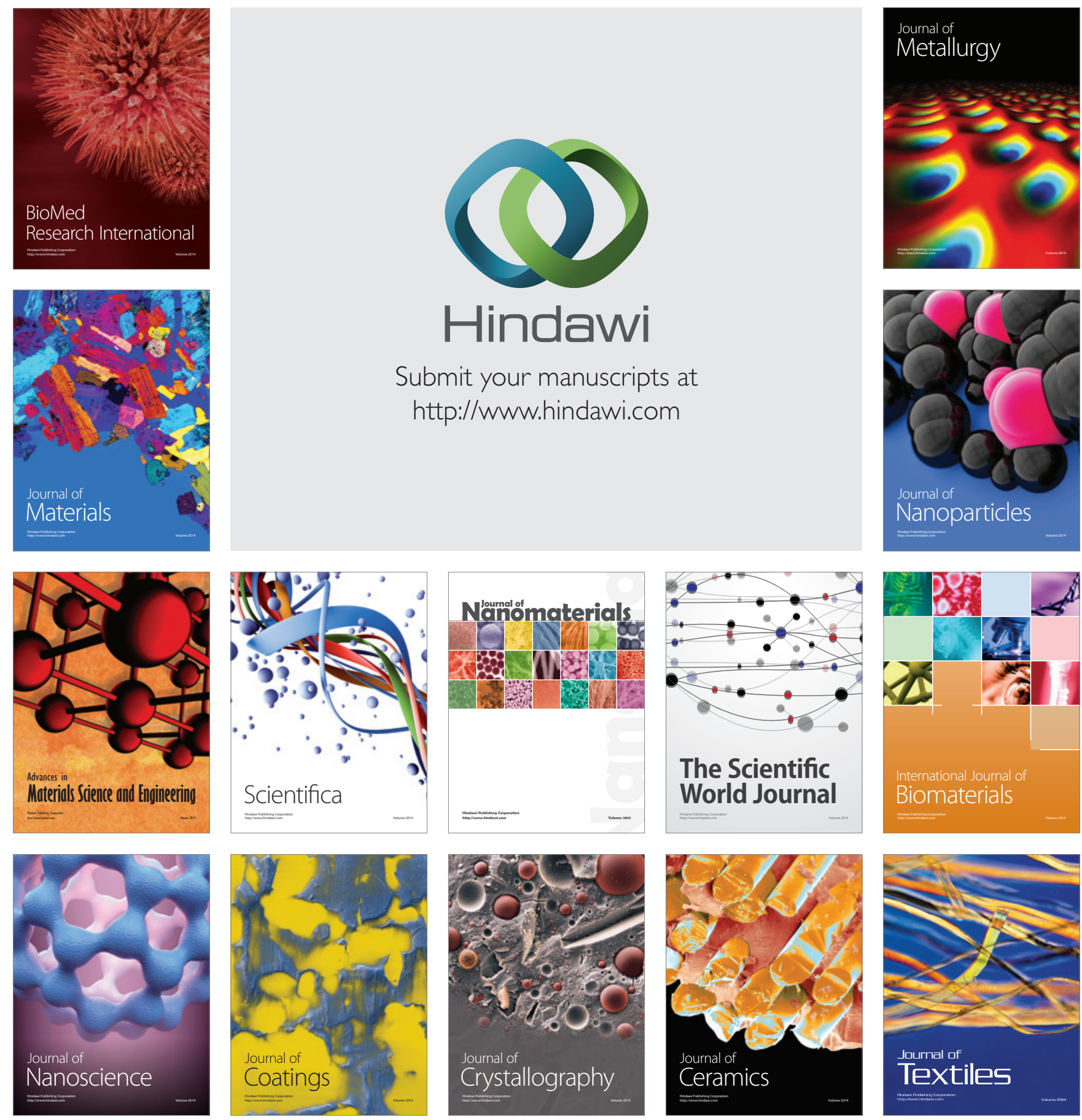